Pacific Journal of Mathematics

INCREASING PATHS ON THE ONE-SKELETON OF A CONVEX
COMPACT SET IN A NORMED SPACE 


\title{
INCREASING PATHS ON THE ONE-SKELETON OF A CONVEX COMPACT SET IN A NORMED SPACE
}

\author{
LEONI DALlA
}

Let $C$ be a convex compact set in a normed space $E$ and let skel $_{1} C$ be the subset of $C$ that contains those boundary points of $C$ which are not centres of 2-dimensional balls in $C$. When $l$ is a continuous functional on $E$, we say that the path $P=g([\alpha, \beta])$ is $l$-strictly increasing if $l\left(g\left(t_{1}\right)\right)<l\left(g\left(t_{2}\right)\right)$ for every $t_{1}, t_{2}$ such that $\alpha \leq t_{1}<t_{2} \leq \beta$. D. G. Larman proved the existence of an $l$-strictly increasing path on the one skeleton of $C$ with $l(g(\alpha))=\min _{x \in C} l(x)$ and $l(g(\beta))=$ $\max _{x \in C} l(x)$.

In this paper we prove a theorem concerning the number of $l$-strictly increasing paths on the one-skeleton of $C$, that are mutually disjoint and along each of which $l$ assumes values in a range arbitrarily close to its range on $C$.

\section{The results. We quote and prove the following theorem}

THEOREM 1. Let $C$ be a compact convex set of infinite dimension in a normed space $E$ and $l$ be a continuous linear functional on $E$, which is non constant on $C$. Let $\varepsilon>0$ be given, $M=\max _{x \in C} l(x)$ and $m=$ $\min _{x \in C} l(x)$. Then, for every $n=1,2,3, \ldots$ there exist $n$ l-strictly increasing paths, $P_{k}=g_{k}([\alpha, \beta]), k=1,2, \ldots, n$ on the one-skeleton of $C$, such that rel int $P_{i} \cap$ rel int $P_{j}=\varnothing$ with $i \neq j, l\left(g_{k}(\alpha)\right)=m+\varepsilon$ and $l\left(g_{k}(\beta)\right)$ $=M-\varepsilon$ for $k=1,2, \ldots, n$.

Proof. Consider the sets $K_{0}=\{x \in C: l(x)=M-\varepsilon\}$ and $K_{1}=\{x$ $\in C: l(x)=m-\varepsilon\}$. These sets are of infinite dimension and lie on two parallel hyperplanes. We define

$$
A=C \cap\{x \in E: l(x) \geq m+\varepsilon\} \cap\{x \in E: l(x) \leq M-\varepsilon\}
$$

Then we may select $n$ linearly independent vectors $e_{1}, e_{2}, \ldots, e_{n}$ and $n$ linear functionals $l_{1}=l, l_{2}, \ldots, l_{n}$ on $E$ such that the following properties hold:

(i) $l_{1}\left(e_{1}\right)=1, l_{i}\left(e_{i}\right) \neq 0$ for $i=2,3, \ldots, n$ and $l_{i}\left(e_{j}\right)=0$ for $i \neq j$

(ii) Let $E_{n}=\left[e_{1}, e_{2}, \ldots, e_{n}\right]$ be the $n$-dimensional subspace of $E$ spanned by $e_{1}, e_{2}, \ldots, e_{n}$ and $\pi_{0}$ be the projection map on $E$, defined by $\pi_{0}(x)=l_{1}(x) e_{1}+\cdots+l_{n}(x) e_{n}$. Then $\operatorname{dim} \pi_{0}\left(K_{0}\right)=$ $\operatorname{dim} \pi_{0}\left(K_{1}\right)=n-1$. 
From the previous, it follows that $C_{n}=\pi_{0}(A)$ is a convex body in $E_{n}$, $\pi_{0}\left(K_{0}\right)=\left\{x \in C_{n}: l(x)=M-\varepsilon\right\}$ and $\pi_{0}\left(K_{1}\right)=\left\{x \in C_{n}: l(x)=\right.$ $m+\varepsilon\}$.

Let $u \in E_{n}$ be a unit vector perpendicular to $e_{1}$. Then according to the results proved in [3] we may choose a unit vector $u^{\prime} \in E_{n}$ orthogonal to $e_{1}$, as close as we please to $u$ and such that there are no line segments in the direction $u^{\prime}$ on the boundary of $C_{n}-$ rel int $\pi_{0}\left(K_{0}\right)-$ rel int $\pi_{0}\left(K_{1}\right)$. Then the projection $\sigma_{n-1}$ of $E_{n}$ onto the hyperplane $E_{n-1}$ perpendicular to $u^{\prime}$ has an inverse function from bd $\sigma_{n-1}\left(C_{n}\right)-\operatorname{rel}$ int $\sigma_{n-1}\left(\pi_{0}\left(K_{0}\right)\right)$ rel int $\sigma_{n-1}\left(\pi_{0}\left(K_{1}\right)\right)$ back to $C_{n}$.

If $\left\{e_{1}, u_{2}, \ldots, u_{n-1}, u\right\}$ is an orthogonal system in $E_{n}$ then we can choose, using induction, unit vectors $u_{n-1}^{\prime}, \ldots, u_{3}^{\prime}$ orthogonal to $e_{1}$ and as close as we please in direction to the projections of the vectors $u_{n-1}, \ldots, u_{3}$ onto the subspaces $E_{n-1} \subseteq\left[u^{\prime}\right]^{\perp}, \quad E_{n-2} \subseteq\left[u^{\prime}, u_{n-1}^{\prime}\right]^{\perp}, \ldots, \quad E_{3} \subseteq$ $\left[u^{\prime}, u_{n-1}^{\prime}, \ldots, u_{4}^{\prime}\right]^{\perp}$ and in such a way the projections $\sigma_{k}: E_{k} \rightarrow E_{k-1}, k=$ $n-2, \ldots, 3$ have unique inverses from

$$
\begin{aligned}
& \text { bd } \sigma_{k} \circ \sigma_{k+1} \circ \cdots \circ \sigma_{n-1}\left(C_{n}\right)-\operatorname{relint} \sigma_{k} \circ \sigma_{k+1} \circ \cdots \circ \sigma_{n-1}\left(\pi_{0}\left(K_{0}\right)\right) \\
& \quad-\operatorname{relint} \sigma_{k} \circ \sigma_{k+1} \circ \cdots \circ \sigma_{n-1}\left(\pi_{0}\left(K_{1}\right)\right)
\end{aligned}
$$

back to $\sigma_{k+1} \circ \cdots \circ \sigma_{n-1}\left(C_{n}\right)$. We complete the orthonormal system $u^{\prime}, u_{n-1}^{\prime}, \ldots, u_{2}^{\prime}, u_{1}^{\prime}$ by taking $u_{1}^{\prime}=e_{1}$ and $u_{2}^{\prime}$ to be the unit vector perpendicular to $u^{\prime}, u_{n-1}^{\prime}, \ldots, u_{3}^{\prime}, u_{1}^{\prime}=e_{1}$ and closest to $u_{2}$.

Write now $\omega_{u^{\prime}}=\sigma_{2} \circ \cdots \circ \sigma_{n-1}$ for the projection of $E_{n}$ on the two dimensional subspace $E_{2}$. For each $t$ such that $m+\varepsilon \leq t \leq M-\varepsilon$, we define by $\xi_{0}(t)$ the point on the line segment $\left\{x \in \omega_{u^{\prime}}\left(C_{n}\right): l_{1}(x)=t\right\}$ whose second coordinate attains its maximum value. On the other hand we may suppose, by making appropriate transformation of $C$, that there exists a cylinder $B$ in the convex body $C_{n}$ of $E_{n}$ such that $B=$ $\overline{\operatorname{con}}\left(S_{0} \cup S_{1}\right)$, where $S_{0}$ and $S_{1}$ are $(n-1)$-dimensional balls of diameter $\delta$ with the property $S_{i} \subseteq$ relint $\pi_{0}\left(K_{i}\right), i=0,1$ and the axis of $B$ in the direction of $e_{1}$.

Let $\varepsilon_{0}$ be such that $0<\varepsilon_{0}<\min \left\{d\left(\mathrm{bd} \pi_{0}\left(K_{0}\right), S_{0}\right), d\left(\mathrm{bd} \pi_{0}\left(K_{1}\right), S_{1}\right)\right\}$ where $d$ is the usual distance between two sets. The convexity of $C_{n}$ implies $d\left(\mathrm{bd} C_{n}-\pi_{0}\left(K_{0}\right)-\pi_{0}\left(K_{1}\right), B\right)>\varepsilon_{0}$. Then there exist a linear functional $l_{u^{\prime}}$ on $E_{n}$ such that $l_{u^{\prime}}\left(u^{\prime}\right)=0, l_{u^{\prime}}\left(u_{2}^{\prime}\right)=1$ and $l_{u^{\prime}}\left(\xi_{0}(t)\right)>\varepsilon_{0}$ $+\delta / 2>0$.

Now let $\xi_{0}^{\prime}(t)$ be the point on the line segment $\left\{x \in \omega_{u^{\prime}}\left(C_{n}\right)\right.$ : $\left.l_{1}(x)=t\right\}$ whose second coordinate attains its minimum value, then $l_{u^{\prime}}\left(\xi_{0}^{\prime}(t)\right)<-\left(\varepsilon_{0}+\delta / 2\right)<0$. Because of the choice of $u^{\prime}, u_{n-1}^{\prime}, \ldots, u_{3}^{\prime}$ the inverse function $\omega_{u^{\prime}}^{-1}$ is uniquely defined from the curves $\xi_{0}(t)$ and $\xi_{0}^{\prime}(t)$ 
back to the one-skeleton of $C_{n}$. Consider now $x_{0}(t)=\omega_{u^{\prime}}^{-1}\left(\xi_{0}(t)\right)$ and $x_{0}^{\prime}(t)=\omega_{u^{\prime}}^{-1}\left(\xi_{0}^{\prime}(t)\right)$ where $m+\varepsilon \leq t \leq M-\varepsilon$. Then $x_{0}(t)$ and $x_{0}^{\prime}(t)$ where $m+\varepsilon \leq t \leq M-\varepsilon$ are paths on the one-skeleton of $C_{n}$. By construction $l_{1}\left(x_{0}(t)\right)=t, l_{1}\left(x_{0}^{\prime}(t)\right)=t$,

$$
l_{u^{\prime}}\left(x_{0}(t)\right)>\varepsilon_{0}+\frac{\delta}{2}, \quad l_{u^{\prime}}\left(x_{0}^{\prime}(t)\right)<-\left(\varepsilon_{0}+\frac{\delta}{2}\right)
$$

$$
\text { for } m+\varepsilon \leq t \leq M-\varepsilon \text {. }
$$

We say then that $\left\{x_{0}(t), m+\varepsilon \leq t \leq M-\varepsilon\right\}$ and $\left\{x_{0}^{\prime}(t), m+\varepsilon \leq t \leq\right.$ $M-\varepsilon\}$ are paths on the one-skeleton of $C_{n}$ "in the direction near $u$ ". Following the methods developed in Theorem 1 in [2] we construct two $l$-strictly increasing paths $z_{0}(t)$ and $z_{0}^{\prime}(t), m+\varepsilon \leq t \leq M-\varepsilon$ on the one-skeleton of $A$ such that

$$
\begin{gathered}
l_{1}\left(z_{0}(t)\right)=t, \quad l_{1}\left(z_{0}^{\prime}(t)\right)=t \quad \text { and } \\
\left\|\pi_{0}\left(z_{0}(t)\right)-x_{0}(t)\right\|<\frac{\varepsilon_{0}}{3}, \quad\left\|\pi_{0}\left(z_{0}^{\prime}(t)\right)-x_{0}^{\prime}(t)\right\|<\frac{\varepsilon_{0}}{3} \\
\text { where } m+\varepsilon \leq t \leq M-\varepsilon .
\end{gathered}
$$

From relations (1) and (2) it follows that

$$
\begin{gathered}
l_{u^{\prime}}\left(\pi_{0}\left(z_{0}(t)\right)\right)>\frac{2}{3} \varepsilon_{0}+\frac{\delta}{2}, \quad l_{u^{\prime}}\left(\pi_{0}\left(z_{0}^{\prime}(t)\right)\right)<-\left(\frac{2}{3} \varepsilon_{0}+\frac{\delta}{2}\right) \\
\text { and } \quad \begin{array}{l}
\pi_{0}\left\{z_{0}(t): m+\varepsilon \leq t \leq M-\varepsilon\right\} \cap B=\varnothing, \\
\pi_{0}\left\{z_{0}^{\prime}(t): m+\varepsilon \leq t \leq M-\varepsilon\right\} \cap B=\varnothing .
\end{array}
\end{gathered}
$$

As (2) holds we may say that $z_{0}(t), z_{0}^{\prime}(t)$ are paths on the one-skeleton of $A$ in the direction near $u$ and we write $z_{0}=z_{u}$ and $z_{0}^{\prime}=z_{u}^{\prime}$.

Let $S$ be the unit ball in $E^{n}$, lying on the hyperplane $l_{1}(x)=0$ and let $\theta$ be a positive number such that $0<\theta<(1 / 2 d)\left(\delta / 2+\varepsilon_{0} / 3\right)$ where $d=\operatorname{diam} C_{n}$. The compactness of $S$ implies the existence of unit vectors $u_{1}, u_{2}, \ldots, u_{m}$ such that for every unit vector $u$ in $S$, there exists $i_{0} \in$ $\{1,2, \ldots, m\}$ with $\left\|u-u_{i_{0}}\right\|<\theta$. Let $Z_{u_{t}}\left\{z_{u_{t}}(t), m+\varepsilon \leq t \leq M-\varepsilon\right\}$ and $Z_{u_{m+t}}=\left\{z_{u_{t}}^{\prime}(t), m+\varepsilon \leq t \leq M-\varepsilon\right\}$ where $i=1,2, \ldots, m$ be paths on the one-skeleton of $A$ in the direction near $u_{i}$. Let $j\left(Z_{u_{1}}, Z_{u_{2}}, \ldots, Z_{u_{i}}\right)$ be the junction set of the paths $Z_{u_{1}}, Z_{u_{2}}, \ldots, Z_{u_{i}}$. Suppose now that card $j\left(Z_{u_{1}}, Z_{u_{2}}, \ldots, Z_{u_{\lambda-1}}\right)<+\infty$ and card $j\left(Z_{u_{1}}, Z_{u_{2}}, \ldots, Z_{u_{\lambda}}\right)=+\infty$ for some $\lambda$ such that $1 \leq \lambda \leq 2 m$. Renaming, if necessary, the paths $Z_{u_{1}}, Z_{u_{2}}, \ldots, Z_{u_{\lambda}}$ we consider the greatest integer $k$ such that $1 \leq k \leq \lambda-$ 1 , card $j\left(Z_{u_{i}}, Z_{u_{\lambda}}\right)<\infty$ for $i=1,2, \ldots, k-1$ and $\operatorname{card} j\left(Z_{u_{i}}, Z_{u_{\lambda}}\right)=$ $+\infty$ for $i=k, k+1, \ldots, \lambda-1$. 
Let

$$
\alpha=\inf \left\{t: t \in[m+\varepsilon, M-\varepsilon] \text { and } z_{u_{k}}(t) \in j\left(Z_{u_{k}}, Z_{u_{\lambda}}\right)\right\}
$$

and

$$
\beta=\sup \left\{t: t \in[m+\varepsilon, M-\varepsilon] \text { and } z_{u_{k}}(t) \in j\left(Z_{u_{k}}, Z_{u_{\lambda}}\right)\right\} .
$$

As $z_{u_{k}}$ and $z_{u_{\lambda}}$ are continuous functions, there is a finite number of closed subintervals $\left[a_{i}, b_{i}\right], i=1,2, \ldots, \nu$, of $[m+\varepsilon, M-\varepsilon]$ with the following properties:

(i) $z_{u_{k}}\left(a_{i}\right)=z_{u_{\lambda}}\left(a_{i}\right), z_{u_{k}}\left(b_{i}\right)=z_{u_{\lambda}}\left(b_{i}\right)$

(ii) $z_{u_{k}}(t) \neq z_{u_{\lambda}}(t), \alpha_{i}<t<b_{i}$ Then

(iii) $\max _{a_{t}<t<b_{i}}\left\|z_{u_{k}}(t)-z_{u_{\lambda}}(t)\right\|>\varepsilon_{0} / 3$ for $i=1,2, \ldots, \nu$.

$$
\begin{aligned}
z_{u_{\lambda}}(m+\varepsilon, a) & \cup z_{k}\left(a, a_{1}\right) \cup \bigcup_{i=1}^{\nu} z_{u_{\lambda}}\left(a_{i}, b_{i}\right) \\
& \cup \bigcup_{i=1}^{\nu-1} z_{u_{k}}\left(b_{i}, a_{i+1}\right) \cup z_{u_{k}}\left(b_{\nu}, b\right) \cup z_{u_{\lambda}}(b, M-\varepsilon)
\end{aligned}
$$

is an $l$-increasing path, $Z_{u_{\lambda}}^{*}$ say, on the one-skeleton of $C$ that is different from $Z_{u_{\lambda}}$ on the set

$$
\Gamma=z_{u_{k}}\left(a, a_{1}\right) \cup \bigcup_{i=1}^{\nu-1} z_{u_{k}}\left(b_{i}, a_{i+1}\right) \cup z_{u_{k}}\left(b_{\nu}, b\right) .
$$

By construction the set $\Gamma$ is within distance $\varepsilon_{0} / 3$ from $Z_{u_{\lambda}}$, hence we have

$$
\left\|z_{u_{\lambda}}(t)-z_{u_{\lambda}}^{*}(t)\right\|<\varepsilon_{0} / 3 \text { for every } t \in[m+\varepsilon, M-\varepsilon]
$$

As card $j\left(Z_{u_{i}}, Z_{u_{\lambda}}^{*}\right)<+\infty$ for $i=1,2, \ldots, k$, we can replace $Z_{u_{\lambda}}$ by $Z_{u_{\lambda}}^{*}$ for every $\lambda=1,2, \ldots, 2 m$ with card $j\left(Z_{u_{1}}, \ldots, Z_{u_{\lambda-1}}\right)<+\infty$ and card $j\left(Z_{u_{1}}, \ldots, Z_{u_{\lambda}}\right)=+\infty$. Then card $j\left(Z_{u_{1}}^{*}, \ldots, Z_{u_{2 m}}^{*}\right)<+\infty$ and using (3) and (4) we get $\left|l_{u^{\prime}}\left(\pi_{0}\left(z_{u_{\lambda}}^{*}(t)\right)\right)\right|>\delta / 2+\varepsilon_{0} / 3$ where $u^{\prime} \in S,\left\|u^{\prime}-u_{\lambda}\right\|$ $<\theta$.

Now we can define the graph $G$ with vertex set $V=\left\{K_{0}\right\} \cup\left\{K_{1}\right\} \cup$ $j\left(Z_{u_{1}}^{*}, \ldots, Z_{u_{2 m}}^{*}\right)$, where an ordered pair of these nodes is said to form a directed subgraph of $G$ if they are joined by an $l$-increasing arc from $\bigcup_{i=1}^{2 m} Z_{u_{i}}^{*}$, which contains no other node of $G$. The required result now follows from Menger-Whitney theorem for the finite graph $G$, if we are able to show that the removal of $(n-1)$ vertices from $j\left(Z_{u_{1}}^{*}, \ldots, Z_{u_{2 m}}^{*}\right)$ still allows an $l$-increasing path running from $K_{0}$ to $K_{1}$. 
Let $y_{1}, y_{2}, \ldots, y_{n-1}$ be $(n-1)$ vertices from $j\left(Z_{u_{1}}^{*}, \ldots, Z_{u_{2 m}}^{*}\right)$. For the points $\pi_{0}\left(y_{1}\right), \pi_{0}\left(y_{2}\right), \ldots, \pi_{0}\left(y_{n-1}\right)$ of $E_{n}$, there exists a linear functional $l^{\prime}$ on $E_{n}$ such that $l^{\prime}\left(\pi_{0}\left(y_{i}\right)\right) \geq 0, i=1,2, \ldots, n-1, l^{\prime}\left(e_{1}\right)=0$ and $l^{\prime}(v)=1$ for some $v \in S$. Let now $u \in S$ be an arbitrary vector such that $l^{\prime}(u)=0$ and $l_{1}(u)=0$. For the vector $u$ there exists a vector $u_{k} \in S$ such that $\left\|u-u_{k}\right\| \leq \theta$. Let $Z_{u_{m+k}}^{*}$ be the path on the one-skeleton of $C$ in the direction near $u_{k}$, with

$$
l_{u_{k}}\left(\pi_{0}\left(z_{u_{m+k}}^{*}(t)\right)\right)<-\left(\frac{\delta}{2}+\frac{\varepsilon_{0}}{3}\right), \quad m+\varepsilon \leq t \leq M-\varepsilon
$$

We can also select $u$ in such a way that $l^{\prime}(u)=0$ and $l_{1}(u)=0$ for which the corresponding $l_{u_{k}}$ has the property $l_{u_{k}}\left(v^{\prime}\right)=1$ for some $v^{\prime} \in S$ with $\left\|v-v^{\prime}\right\|<\theta$.

Now, we may suppose that

$$
\begin{array}{ll}
l_{u_{k}}\left(\pi_{0}\left(y_{i}\right)\right) \geq 0 & \text { for } i=1,2, \ldots, \mu \text { and } \\
l_{u_{k}}\left(\pi_{0}\left(y_{i}\right)\right)<0 & \text { for } i=\mu+1, \ldots, n-1
\end{array}
$$

Relations (5) and (6) imply that

$$
\pi_{0}\left(y_{i}\right) \notin \pi_{0}\left(Z_{u_{m+k}}^{*}\right) \text { for } i=1,2, \ldots, \mu
$$

We have that $l^{\prime}(v)=1, l_{u_{k}}\left(v^{\prime}\right)=1$ with $\left\|v-v^{\prime}\right\|<\theta$ and $l^{\prime}\left(\pi_{0}\left(y_{i}\right)\right) \geq 0$, $l_{u_{k}}\left(\pi_{0}\left(y_{i}\right)\right)<0$ for $i=\mu+1, \ldots, n-1$. Hence

$$
l_{u_{k}}\left(\pi_{0}\left(y_{i}\right)\right) \geq-d \theta-\left(\frac{\delta}{2}+\frac{\varepsilon_{0}}{3}\right), \quad i=\mu+1, \ldots, n-1 .
$$

From (5) and (8) we have that $\pi_{0}\left(y_{i}\right) \notin \pi_{0}\left(Z_{u_{m+k}}^{*}\right)$ for $i=\mu+1, \ldots, n-$ 1. Hence, from (7) and (8) follows that $y_{i} \notin Z_{u_{m+k}}^{*}, i=1,2, \ldots, n-1$ which completes the proof of the theorem.

From the above theorem one can deduce the following corollaries whose proofs are omitted as obvious.

Corollary 1. Suppose that $C$ and $l$ are defined as in Theorem 1, the faces

$$
F_{0}=\left\{x \in C: l(x)=\min _{y \in C} l(y)\right\} \quad \text { and } \quad F_{1}=\left\{x \in C: l(x)=\max _{y \in C} l(y)\right\}
$$

are such that the dimension of $F_{0}^{\prime} \cap F_{1}^{\prime}$ is infinite, where $F_{0}^{\prime}$ and $F_{1}^{\prime}$ are the corresponding subspaces translates of $F_{0}$ and $F_{1}$ correspondingly. Then for every $n=1,2, \ldots$ there are $n$ l-strictly increasing paths on the one-skeleton of $C$ mutually disjoint that join $F_{0}$ to $F_{1}$. 
COROllary 2. Suppose that $C$ a compact convex set of infinite dimension in a normed space E. Then the one-dimensional Hausdorff measure of the one-skeleton is infinite.

We may remark that the $n$-dimensional Hausdorff measure of the $n$-skeleton of a set $C$ as in Corollary 2 is infinite for every $n=1,2, \ldots$ For a direct proof of this result see [1].

\section{REFERENCES}

[1] Leoni Dalla, The n-dimensional Hausdorff measure of the n-skeleton of a convex weakly compact set, Mathematische Nachrichten, (to appear).

[2] D. G. Larman, On the one-skeleton of a compact convex set in a Banach space, Proc. London Math. Soc., (3) 34 (1977), 117-144.

[3] D. G. Larman and C. A. Rogers, Increasing paths on the one-skeleton of a convex body and the directions of line segments on the boundary of a convex body, Proc. London Math. Soc., 23 (1971), 683-698.

Received March 19, 1985.

DEPaRTMENT OF MATHEMATICS

SECTION OF Mathematical ANalysis

AND ITS APPLICATIONS

PANEPISTEMIOPOLIS, 15781 ATHENS

GREECE 


\section{PACIFIC JOURNAL OF MATHEMATICS EDITORS}

\author{
V. S. VARADARAJAN \\ (Managing Editor) \\ University of California \\ Los Angeles, CA 90024 \\ Herbert Clemens \\ University of Utah \\ Salt Lake City, UT 84112 \\ R. FINN \\ Stanford University \\ Stanford, CA 94305
}

\author{
HERMANN FLASCHKA \\ University of Arizona \\ Tucson, AZ 85721 \\ RAMESH A. GANGOLLI \\ University of Washington \\ Seattle, WA 98195 \\ VAUGHAN F. R. JONES \\ University of California \\ Berkeley, CA 94720 \\ ROBION KIRBY \\ University of California \\ Berkeley, CA 94720
}

C. C. MOORE

University of California

Berkeley, CA 94720

H. SAMELSON

Stanford University

Stanford, CA 94305

HAROLD STARK

University of California, San Diego La Jolla, CA 92093

\section{ASSOCIATE EDITORS}
R. ARENS
E. F. BECKENBACH (1906-1982)
B. H. NEUMANN
F. WOLF
K. YosHIDA

\section{SUPPORTING INSTITUTIONS}

\begin{abstract}
UNIVERSITY OF ARIZONA
UNIVERSITY OF BRITISH COLUMBIA

CALIFORNIA INSTITUTE OF TECHNOLOGY

UNIVERSITY OF CALIFORNIA

MONTANA STATE UNIVERSITY

UNIVERSITY OF NEVADA, RENO

NEW MEXICO STATE UNIVERSITY OREGON STATE UNIVERSITY
\end{abstract}

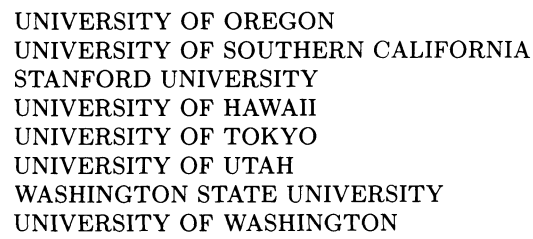

The Supporting Institutions listed above contribute to the cost of publication of this Journal, but they are not owners or publishers and have no responsibility for its content or policies.

Mathematical papers intended for publication in the Pacific Journal of Mathematics should be in typed form or offset-reproduced (not dittoed), double spaced with large margins. Please do not use built up fractions in the text of the manuscript. However, you may use them in the displayed equations. Underline Greek letters in red, German in green, and script in blue. The first paragraph must be capable of being used separately as a synopsis of the entire paper. In particular it should contain no bibliographic references. Please propose a heading for the odd numbered pages of less than 35 characters. Manuscripts, in triplicate, may be sent to any one of the editors. Please classify according to the scheme of Math. Reviews, Index to Vol. 39. Supply name and address of author to whom proofs should be sent. All other communications should be addressed to the managing editor, or Elaine Barth, University of California, Los Angeles, California 90024.

There are page-charges associated with articles appearing in the Pacific Journal of Mathematics. These charges are expected to be paid by the author's University, Government Agency or Company. If the author or authors do not have access to such Institutional support these charges are waived. Single authors will receive 50 free reprints; joint authors will receive a total of 100 free reprints. Additional copies may be obtained at cost in multiples of 50 .

The Pacific Journal of Mathematics is issued monthly as of January 1966. Regular subscription rate: $\$ 190.00$ a year (5 Vols., 10 issues). Special rate: $\$ 95.00$ a year to individual members of supporting institutions.

Subscriptions, orders for numbers issued in the last three calendar years, and changes of address should be sent to Pacific Journal of Mathematics, P.O. Box 969, Carmel Valley, CA 93924, U.S.A. Old back numbers obtainable from Kraus Periodicals Co., Route 100, Millwood, NY 10546.

The Pacific Journal of Mathematics at P.O. Box 969, Carmel Valley, CA 93924 (ISSN 0030-8730) publishes 5 volumes per year. Application to mail at Second-class postage rates is pending at Carmel Valley, California, and additional mailing offices. Postmaster: send address changes to Pacific Journal of Mathematics, P.O. Box 969, Carmel Valley, CA 93924.

PUBLISHED BY PACIFIC JOURNAL OF MATHEMATICS, A NON-PROFIT CORPORATION Copyright (C) 1986 by Pacific Journal of Mathematics 


\section{Pacific Journal of Mathematics}

Vol. 124, No. $2 \quad$ June, 1986

Philip Lee Bowers, Nonshrinkable "cell-like" decompositions of $s \ldots \ldots .257$

Aurelio Carboni and Ross Street, Order ideals in categories .......... 275

Leoni Dalla, Increasing paths on the one-skeleton of a convex compact set in

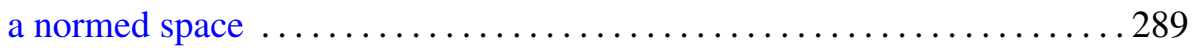

Jim Hoste, A polynomial invariant of knots and links ............... 295

Sheldon Katz, Tangents to a multiple plane curve ................... 321

Thomas George Lucas, Some results on Prüfer rings $\ldots \ldots \ldots \ldots \ldots \ldots 33$

Pham Anh Minh, Modular invariant theory and cohomology algebras of

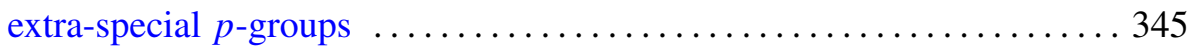

Ikuko Miyamoto, On inclusion relations for absolute Nörlund

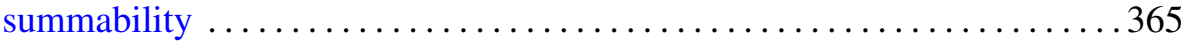

A. Papadopoulos, Geometric intersection functions and Hamiltonian flows on the space of measured foliations on a surface ............. 375

Richard Dean Resco, J. Toby Stafford and Robert Breckenridge

Warfield, Jr., Fully bounded $G$-rings $\ldots \ldots \ldots \ldots \ldots \ldots \ldots \ldots \ldots 4$

Haskell Paul Rosenthal, Functional Hilbertian sums .................417

Luen-Fai Tam, Regularity of capillary surfaces over domains with corners: borderline case ................................. 469

Hugh C. Williams, The spacing of the minima in certain cubic lattices .....483 